\title{
EFEITOS DE SOJA BT E NÃO BT SOBRE INSETOS NÃO-ALVO: ÁCAROS, TRIPES E COLEÓPTEROS
}

\section{EFFECTS OF BT AND NON-BT SOYBEAN ON NON-TARGETED INSECTS: MITES, THRIPS AND COLEOPTERAN}

\section{Luana Fernandes Barros ${ }^{1}$; Gabrielle Cruz Macena ${ }^{2}$; Edson Araújo de Amorim ${ }^{3}$; Mauricélia Ferreira Almeida 4; Edmar de Souza Tuelher 5}

DOI: https://doi.org/10.31692/978-65-991061-7-0.282-287

\section{INTRODUÇÃO}

A cultura da soja é uma das mais importantes culturas agrícolas, tendo sua utilização destinada tanto para alimentação humana quanto animal, para a extração de óleo vegetal, entre outras (MISSÃO 2006). Por ser uma monocultura abundante, as plantas de soja sofrem ataques de diversas pragas, principalmente lagartas desfolhadoras da ordem Lepidoptera, como Anticarsia gemmatalis e Chrysodeixis includens, que são das pragas chaves desta cultura (SOSA-GÓMEZ et al., 2010).

Para minimizar os danos destas lagartas tem sido amplamente utilizada no Brasil e no mundo cultivares de soja com resistência genética a estes insetos e que produzem toxinas de Bacillus thuringiensis (Bt) que atuam como inseticidas (JAMES, 2015). Com isso, há uma menor utilização de inseticidas nos cultivares $B t$, podendo favorecer insetos pragas que não são afetados da toxina $B t(C A T T A N E O$ et al., 2006).Estes organismos podem ser expostos a proteínas Bt por um longo tempo, embora não sejamos alvos diretos destas culturas (ANDOW \&HILBECK, 2004). Nesse sentido, as plantas geneticamente modificadas resistentes a insetos (plantas $\mathrm{Bt}$ ) tem apresentado eficiência no manejo de pragas em diversas culturas no mundo, mas ainda pouco se conhece sobre seus efeitos em organismos não-alvo, como outra pragas e ou inimigos naturais. Assim, o objetivo do presente estudo foi avaliar e comparar a densidadee a flutuação populacional de artrópodes não-alvo em soja Bt e não Bt, como os ácaros da família Tetranychidae, tripes e a injúriade coleópteros do gênero Cerotoma sp.

\section{FUNDAMENTAÇÃO TEÓRICA}

A produtividade da cultura é definida pela interação entre a planta, o ambiente de

1 Engenharia Agronômica, Universidade Estadual da Região Tocantina do Maranhão (UEMASUL), luananandes9@gmail.com

${ }^{2}$ Engenharia Agronômica, UEMASUL, macenabi@gmail.com

${ }^{3}$ Engenharia Agronômica, UEMASUL, edsonamorins@ hotmail.com

${ }^{4}$ Doutora em Entomologia, UEMASUL, mauricellia1@ @otmail.com

${ }^{5}$ Doutorem Entomologia, UEMASUL, edmar.tuelher@gmail.com 
produção e o manejo (MAUAD et al. 2010). Contudo a cultura da soja ainda possui sérios problemas ligados ao ataque de pragas durante todo o seu ciclo, resultando em reduções na produção que podem chegar a 15,6\% do total produzido (FAO, 2013). Além das pragas chaves, podemos identificar o ataque de outros organismos, como ácaros, tripes e coleópteros (SOSA-GÓMEZ et al., 2010).

Os ácaros são encontrados na superfície inferior e superior dos folíolos e devido à sua alimentação, comprometem o desenvolvimento normal da planta, aumentando as perdas de água e reduzem a capacidade fotossintética das plantas (MORAES; FLECHTMANN, 2008).As vaquinhas do gênero Cerotoma são coleópteros que podem causar desfolhamento severo, causando injúrias principalmente nas partes mais tenras das plantas, ou seja, as folhas mais novas (LINK\& COSTA, 1978).As larvas,por sua vez, em grande número, podem reduzir a disponibilidade de nitrogênio devido a se alimentarem dos nódulos de rizóbio nas raízesresponsáveis pela fixação de nitrogênio para as plantas (HOFFMANN-CAMPO et al., 2000). Já os tripes podem ser encontrados em todas as partes das plantas, principalmente nas folhas jovens e flores, e suas injúriasresultam em manchas necróticas devida à destruição celular do tecido vegetal, e podem ainda transmitir viroses (MOUND, 2005).

Assim, estes organismos-pragas podem ocasionar grandes danos fisiológicos na cultura, podendo comprometer a produção da soja. No entanto, a dinâmica populacional destesorganismos não alvo em cultivares de soja Bt e não Bt ainda não é bem descrita. Desta forma, torna-se importante conhecer a incidência e densidade populacional desses insetos não-alvo em soja Bt e não Bt, para a correta tomada de decisão de controle.

\section{METODOLOGIA}

O presente experimento foi desenvolvido em uma área agrícola, no município de Montes Altos, MA, localizado à 63 quilômetros da cidade de Imperatriz-MA. Foram utilizadasduas cultivares de soja Bt, M8349 IPRO e M8372 IPRO (Monsanto do Brasil S.A.) e a cultivar não Bt, 99R09 (Pioneer Sementes).O delineamento utilizado foi de blocos ao acaso, com três tratamentos e cinco repetições.

O plantio foi realizado manualmente com a semeadura de 16 sementes por metro linear numa profundidade de $3 \mathrm{~cm}$ em sulcos espaçados a cada $45 \mathrm{~cm}$. Foi realizada uma adubação de plantio nos sulcos com $400 \mathrm{~kg} / \mathrm{h}$ da formula comercial NPK (4-30-10). As sementes foram previamente inoculadas com Bradyrhizobium japonicum (isolados SEMIA 5079+SEMIA 5080) e turfa bacteriana, conforme recomendação do fabricante. Cada parcela experimental foi constituída de 6 linhas de 5 metros espaçadas de $45 \mathrm{~cm}$. A parcela útil foi 
constituída das duas linhas centrais, descartando-se $50 \mathrm{~cm}$ de cada lado da parcela naparcela útil com uma área útil de 3,6 $\mathrm{m}^{2}$. Após 21 dias do plantio foi realizado um desbaste deixandose 12 plantas por metro linear.

Para a quantificação de população de pragas foram realizadas amostras semanais, entre 9:00 e 10:00 h, que se iniciaram aos 30 dias após o plantio.Foram coletadas dez trifolíolos por parcela no terço superior das plantas que foram posteriormente levados ao Laboratório de Entomologia Agrícola da Universidade Estadual da Região Tocantina do Maranhão (UEMASUL). Foram avaliadas a incidência de ácaros (Tetranychus sp.) e tripes (Thrips sp.) e os danos por coleópteros (Cerotoma sp.) através de inspeção visualcom o auxílio de microscópio estereoscópio, contabilizando o número de ácaros e insetos e dos sintomas provocados pelo ataque de coleópteros.

O número de ácaros, tripes e a desfolha por coleópteros foram submetidos à análise de variância por medidas repetidas (GREEN, 1993) utilizando o procedimento PROC GLM (SAS INSTITUTE, 1989).

\section{RESULTADOS E DISCUSSÕES}

Não houve efeito das cultivares na incidência dos insetos não alvo avaliados, sendo evidenciado apenas efeito do tempo sobre a densidade e a flutuação populacional dos artrópodes. (Tabela 1, Fig. 1A-C). O efeito do tempo na flutuação populacional destes artrópodes resultou no aumento da densidade de ácaros (Tetranychus sp.)e aumento das injúriasporCerotoma sp. com o decorrer do tempo, coincidindo com o final do ciclo da cultura (Fig. 1A-B), ao contrário da maior incidênciade Thrips sp., que ocorreu no início da fase reprodutiva (Figura 1C). No entanto, a variaçãoao longo de tempo não diferiu entre os cultivares, sejam estes Bt (M8349 IPRO e M8372 IPRO) ou não Bt (99R09) (Tabela 1, Fig. $1 \mathrm{~A}-\mathrm{C})$.

A fenologia da planta pareceu ser o principal fator a influenciar a incidência destes insetos, principalmente a incidência de ácaros, que coincidiu com o final da fase reprodutiva e a senescência da cultura (Fig. 1A) e também a desfolha causada por coleópteros (Fig. 1B). Em relação a densidade de tripes, o índice mais alto de infestação foi encontrado na terceira avaliação, caindo subitamente nas avaliações seguintes e mantendo este baixo índice até o final do experimento (Fig. 1C). As injúriasdevido ao ataque coleópteros, em que foram contabilizados os números de perfurações causados por Cerotoma sp. também foram maiores no final do ciclo. Adicionalmente, também não foi observada diferença significativa na desfolha entre os cultivares avaliados.Este aumento na 
desfolhapor este inseto pode ser devido à ausência da aplicação de inseticidas na área e também ao período de ausência de chuvas, possibilitando ao aumento da infestação dos insetos (ROGGIA, 2010) e atingindo o ápice no final do ciclo da cultura. Assim, os fatores climáticos associados à fenologia das plantas explicam a dinâmica populacional destas espécies quecontribuem em maior grau para a incidência e aumento populacional desses insetos praga (MOUND, 2005).

Portanto, dentre as cultivares avaliadas não foram encontradas diferenças na densidade flutuação populacional dos insetos não alvo encontrados neste ensaio. Portanto, entre os cultivares Bt e não Bt avaliados, as estratégias para manejo destes insetos aparentemente serão similares, não havendo aumento da incidência destas espécies nas cultivares Bt.

Tabela 1: ANOVA de medidas repetidas para níveis de incidênciade insetos não alvo em cultivares de soja Bt e não Bt. Os dados foram coletados semanalmentea partir de 7 de junho de 2018 no município de Montes

Altos/MA. Fonte: Próprio autor, 2018.

\begin{tabular}{|c|c|c|c|c|c|c|c|c|}
\hline \multirow[t]{2}{*}{ Fontes de variação } & \multicolumn{3}{|c|}{ Tetranychus sp. } & \multicolumn{2}{|c|}{ Thrips sp. } & \multicolumn{3}{|c|}{ Cerotoma sp. } \\
\hline & $\mathrm{gl}$ & $\mathrm{F}$ & $P$ & $\mathrm{~F}$ & $P$ & $\mathrm{gl}$ & $\mathrm{F}$ & $P$ \\
\hline \multicolumn{9}{|l|}{ Entre níveis do fator } \\
\hline Cultivar (C) & 2 & 0,21 & 0,81 & 1,21 & 0,27 & 2 & 1,43 & 0,30 \\
\hline Bloco (B) & 4 & 0,69 & 0,62 & 2,78 & 0,11 & 4 & 1,03 & 0,45 \\
\hline Resíduo & 7 & - & - & - & - & 7 & - & - \\
\hline \multicolumn{9}{|c|}{ Dentro dos níveis do fator } \\
\hline Tempo (T) & 6 & 3,43 & $0,04 *$ & 10,69 & $0,01 *$ & 3 & 6,57 & $0,01 *$ \\
\hline $\mathrm{T} \times \mathrm{C}$ & 12 & 0,81 & 0,56 & 1,68 & 0,25 & 6 & 0,27 & 0,29 \\
\hline $\mathrm{T} \times \mathrm{B}$ & 24 & 1,04 & 0,45 & 2,12 & 0,18 & 12 & 0,12 & 0,17 \\
\hline Resíduo & 42 & - & - & - & - & 21 & - & - \\
\hline
\end{tabular}

gl: graus de liberdade; $* P<0.05$.

Figura 1. Densidade e flutuação populacional de insetos praga não alvo em cultivares de soja $B t$ e não Bt:(A) Tetranychus sp. (B) Thrips sp. (C) Cerotoma sp. Montes Altos, MA. 24 de maio a 26 de julho de

A

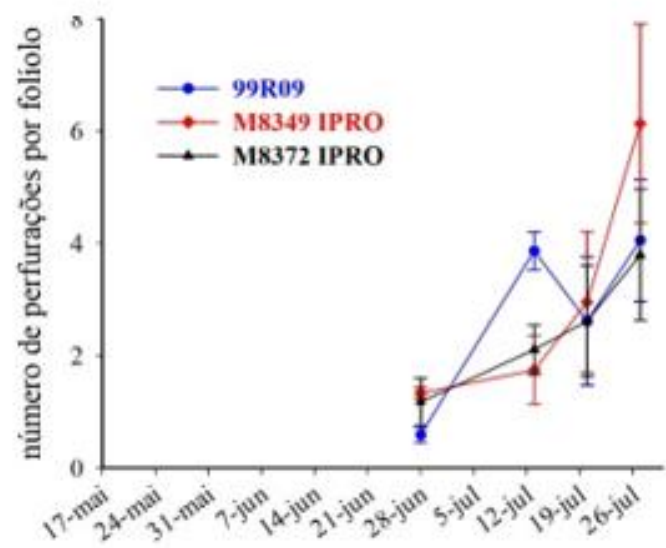

Data da avaliação (dia/mês)

2017. Fonte: Próprio autor, 2018.

B

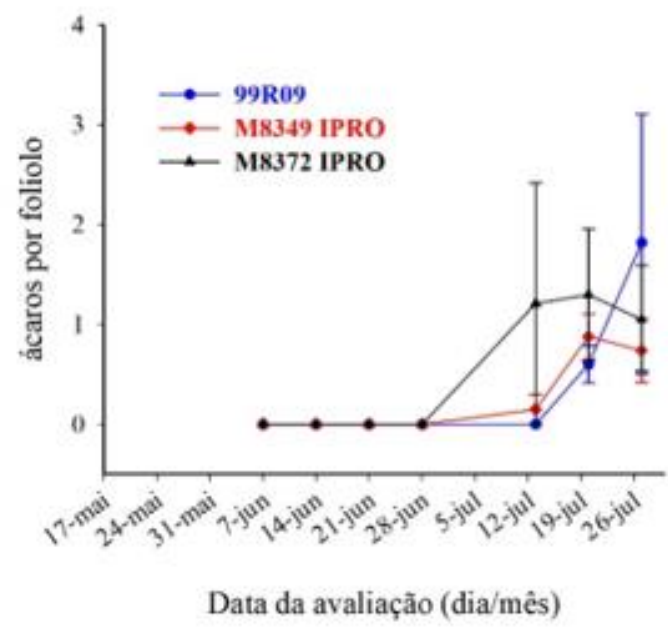

[285] 


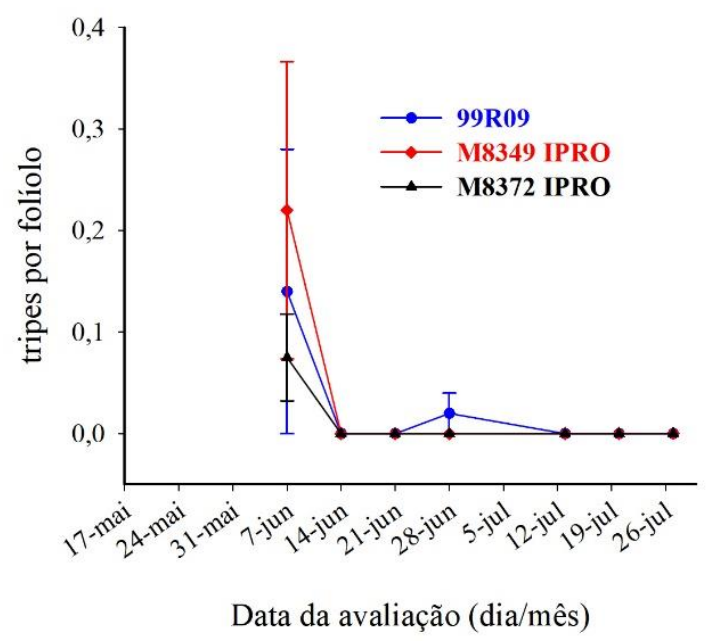

\section{CONCLUSÕES}

As cultivares Bt resistentes a insetos M8349 IPRO e M8372 IPRO afetaram similarmente a dinâmica populacional dos ácaros (Tetranychus sp.), tripes (Thrips sp.) e coleópteros (Cerotoma sp.) se comparada a cultivar não Bt, 99R09, durante o período avaliado no ciclo da cultura da soja. Portanto, as cultivares Bt podem ser utilizadas sem serem esperadas efeitos adversos sobre os insetos não alvo da tecnologia, como ácaros, tripes e o coleópteros Cerotoma sp.

\section{REFERÊNCIAS}

ANDOW, D.A., HILBECK, A. 2004. Science-based risk assessment for non-target effectsof transgenic crops. BioScience. 54: 637-649.

CATTANEO, M.G., YAFUSO, C., SCHMIDT, C., HUANG, C.H., RAHMAN, M. 2006. Farm-scale evaluation of the impacts of transgenic cotton on biodiversity, pesticide use, and yield. Proceedings of the National Academy of Sciences of the USA 103: 7571-7576.

FOOD EN AGRICULTURE ORGANIZATION OF THE UNITED NATIONS-FAO. 2013. Disponível em: http://www.fao.org/brasil/pt/ Acesso em: 14 setembro, 2018.

GREEN, R. H. Application of repeated measures designs in environmental impact and monitoring studies. Australian Journal of Ecology, v. 18, p. 81-98, 1993

HOFFMANN-CAMPO, et al. Pragas da soja no Brasil e seu manejo integrado. Londrina: Embrapa-CNPSo, 2000. 70 p. (Embrapa-CNPSo. Circular Técnica, 30).

JAMES C. Global status of commercialized biotech/GM crops. ISAAA Brief No. 51. ISAAA, Ithaca, New York. 2015.

LINK, D.; COSTA, E. C. Danos causados por crisomelídeos em soja. Revista do Centro de Ciências Rurais, Santa Maria, v. 8, p. 245-250, 1978. 
MAUAD, M.; et al. Influência da densidade de semeadura sobre características agronômicas na cultura da soja. Revista Agrarian, v. 3, n. 9, p. 175-181, 2010.

MISSÃO, M. R. 2006. Soja: origem, classificação, utilização e uma visão abrangente do mercado. Maringá Management: Revista de Ciências Empresariais, v. 3, n.1 - p.7-15,

MOUND, L. A. Thysanoptera: Diversity and Interactions. Annual Review of Entomology, Canberra, v. 50, p. 247-269, 2005.

MORAES, G.J.; FLECHTMANN, C.H.W. Manual de Acarologia, Acarologia Básica e Ácaros de Plantas Cultivadas no Brasil. Ribeirão Preto: Holos Editora,2008.

REZENDE, J. A. M.; ROSSETTO, C. J.; MIRANDA, M. A. C. Comportamento de populações paternais e F1 de soja em relação a Colaspis sp. e Diabrotica speciosa (Germar, 1824). Bragantia, Campinas, v. 39, n. 3, p. 15-20, 1980.

ROGGIA, S. Caracterização de fatores determinantes dos aumentos populacionais de ácaros tetraniquídeos em soja. 2010. Tese (Doutorado em Agronomia) - Escola Superior de Agricultura "Luiz de Queiroz". Universidade de São Paulo, Piracicaba.

SAS INSTITUTE. SAS/STAT User's Guide, Version 6. Cary: SAS INSTITUTE, 1989.

SOSA-GÓMEZ, D.R. et al. Manual de identificação de insetos e outros invertebrados da cultura da soja. Londrina: Embrapa-CNPSo, 2010. 90 p. (Embrapa - CNPSo. Documentos, 269). 